\title{
Fluoxetine disrupts motivation and GABAergic signaling in adolescent female hamsters
}

John L. Shannonhouse, M.S. ${ }^{1}$, Dustin W. DuBois, Ph.D. ${ }^{1,2}$, Annette S. Fincher, B.S. ${ }^{2}$, Alejandra M. Vela, B.S. ${ }^{3}$, Morgan M. Henry, B.S. ${ }^{3}$, Paul J. Wellman, Ph.D. ${ }^{1,4}$, Gerald D. Frye, Ph.D. ${ }^{1,2}$, and Caurnel Morgan, Ph.D. ${ }^{1,3}$

${ }^{1}$ Texas A\&M Institute for Neuroscience, Texas A\&M University, College Station, Texas 77843

${ }^{2}$ Department of Neuroscience \& Experimental Therapeutics, Texas A\&M Health Science Center, Bryan, Texas 77807

${ }^{3}$ Department of Nutrition \& Food Science, Texas A\&M University, College Station, Texas 77843

${ }^{4}$ Department of Psychology, Texas A\&M University, College Station, Texas 77843

Address correspondence to:

Caurnel Morgan, PhD

Akhu Therapeutics, Inc.

2713 Horse Haven Lane

College Station, Texas 77845-6044

Tel: +1-979-458-1849

E-mail: camorgan@akhutherapeutics.com

\section{ACKNOWLEDGEMENTS}

This work was supported by a Texas AgriLife Research Award through funding from the National Institute of Food \& Agriculture of the USDA (H-9230) to CM; Heep Neuroscience Fellowship to JLS; and NIH R01-DA013188 to PJW.

The authors declare no conflict of interest. 


\begin{abstract}
Initial antidepressant treatment can paradoxically worsen symptoms in depressed adolescents by undetermined mechanisms. Interestingly, antidepressants modulate GABAA receptors, which mediate paradoxical effects of other therapeutic drugs, particularly in females. Although the neuroanatomic site of action for this paradox is unknown, elevated GABAA receptor signaling in the nucleus accumbens can disrupt motivation. We assessed fluoxetine's effects on motivated behaviors in pubescent female hamsters - anhedonia in the reward investigational preference (RIP) test as well as anxiety in the anxiety-related feeding/exploration conflict (AFEC) test. We also assessed accumbal signaling by RT-PCR and electrophysiology. Fluoxetine initially worsened motivated behaviors at puberty, relative to adulthood. It also failed to improve these behaviors as pubescent hamsters transitioned into adulthood. Low accumbal mRNA levels of multiple GABAA receptor subunits and GABA-synthesizing enzyme, GAD67, assessed by RTPCR, suggested low GABAergic tone at puberty. Nonetheless, rapid fluoxetine-induced reductions of $\alpha 5 \mathrm{GABAA}$ receptor and BDNF mRNA levels at puberty were consistent with agerelated differences in GABAergic responses to fluoxetine and disruption of the motivational state. Whole-cell patch clamping of accumbal slices also suggested low GABAergic tone by the low amplitude of miniature inhibitory postsynaptic currents (mIPSCs) at puberty. It also confirmed age-related differences in GABAergic responses to fluoxetine. Specifically, fluoxetine potentiated mIPSC amplitude and frequency at puberty, but attenuated the amplitude during adulthood. These results implicate GABAergic tone and GABAA receptor plasticity in adverse motivational responses and resistance to fluoxetine during adolescence.
\end{abstract}

Key Words: accumbens; anhedonia; anxiety; GABAA receptor; maturation 


\section{INTRODUCTION}

Despite the widespread use of antidepressants to treat depression, their use by adolescents is controversial because initial treatment is reported to paradoxically worsen depression and anxiety symptoms, including suicidality (Jick, Kaye et al. 2004, Cusin, Fava et al. 2007). Concerns arising from these side effects led the U.S. Food and Drug Administration to warn of increased risk of suicidality with antidepressant treatment of patients under age 25 (Bridge, Iyengar et al. 2007). In addition, antidepressants exert only modest therapeutic efficacy, particularly during adolescence (Bridge, Iyengar et al. 2007). In a review of 17 randomized clinical trials, four trials showed modest efficacy of adult and youth treatment with fluoxetine, but not other selective serotonin reuptake inhibitors (SSRIs). In contrast, 13 other trials found the efficacies to be indistinguishable from those of placebos (Mann, Emslie et al. 2006). Thus, there is an urgent need to elucidate underpinnings for antidepressant actions on the adolescent brain.

Few studies have assessed emotional responses to continuous antidepressant treatment during adolescence in animal models. West and colleagues (2010) systemically infused adolescent male rats with paroxetine through surgically implanted cannulae, which worsened depression-related behavior. In other studies, however, adolescent male rats administered paroxetine without cannulation (Karanges, Li et al. 2011), and adolescent male mice administered fluoxetine through cannulae (Oh, Zupan et al. 2009) did not show elevations in depression-related behavior. Thus, to our knowledge only one previous study has demonstrated a pro-depressant-like effect of continuous antidepressant treatment in adolescent rodents (West, Ritchie et al. 2010). Two of the studies described above reported anxiogenic effects of antidepressants in adolescent rats or mice (Oh, Zupan et al. 2009, Karanges, Li et al. 2011). Although chronic antidepressant treatment is anxiolytic (Rynn, Puliafico et al. 2011), acute treatment with some SSRI and tricyclic antidepressants worsens anxiety in adult mammals (Kshama, Hrishikeshavan et al. 1990, Spigset 1999, Liu, Garza et al. 2010). Interestingly, initial treatment of rats with fluoxetine induced greater anxiety in adults than in adolescents (Arrant, Coburn et al. 2013), and similar increases in serotonergic signaling in the brain might indicate that other neural systems mediate age-related differences in this effect. Only one of the above studies on adolescent rodents assessed anxiety in adult controls, and found that paroxetine also increased it in adults (Karanges, Li et al. 2011). Thus, the distinction between anxiogenic effects of antidepressants in adults and adolescents needs clarification.

Other studies have assessed adolescent rodents for emotional responses to antidepressant discontinuation. Homberg and colleagues (2011) found elevated depression-related behavior in adolescent male rats after the washout of chronic fluoxetine treatment. In contrast, there was no change in the behavior of adolescent male rats after discontinuation of chronic paroxetine or fluvoxamine treatment (de Jong, Snaphaan et al. 2006), or of adolescent male mice after discontinuation of chronic fluoxetine treatment (Oh, Zupan et al. 2009). Moreover, Iñiguez and colleagues found depression-related behavior in adolescent male rats to be relatively insensitive to fluoxetine, and discontinuation after a high dose was associated with the persistence of antidepressant-like effects in rats and mice (Iniguez, Warren et al. 2010, Iniguez, Alcantara et al. 2014). Two of these studies found that antidepressant discontinuation was anxiogenic (de Jong, Snaphaan et al. 2006, Iniguez, Warren et al. 2010), but the remaining two did not (Oh, Zupan et al. 2009, Homberg, Olivier et al. 2011). Distinguishing continuous from discontinuous treatment is important because discontinuation of SSRI treatment in humans is characterized by the worsening of depression and anxiety symptoms, and changes in GABA signaling are implicated 
(Schatzberg, Haddad et al. 1997). Few discontinuation studies have compared anxiety levels in adolescent and adult rodents. After fluoxetine washout in rats, one study found no effect in adults (Homberg, Olivier et al. 2011), but another found anxiogenic effects in adults, but not in adolescents (Bouet, Klomp et al. 2012).

These studies reveal five gaps in understanding the emotional consequences of adolescent antidepressant treatment. First, the worsening of symptoms by initial treatment is poorly understood. Second, anxiogenic responses to initial antidepressant treatment in adolescents remain to be distinguished from those in adults. Third, neurobiological underpinnings for paradoxical emotional responses have not been established. Fourth, adolescent-specific paradoxical effects on emotionality have not been reported for fluoxetine, the prototypical antidepressant for adolescents. Fifth, female models of adolescent responses to antidepressants are needed.

The objective of the present study was to help bridge these fundamental knowledge gaps, using an adolescent model with paradoxical effects of fluoxetine on motivated (i.e., anhedonic and anxious) behaviors. We used pubescent and adult female hamsters because we have shown previously that they exhibit behaviors reflecting traits for emotional lability (Shannonhouse, Fong et al. 2014, Shannonhouse, York et al. 2014). Although fluoxetine acts on the serotonin system, it also modulates GABAA receptors (Tunnicliff, Schindler et al. 1999, Robinson, Drafts et al. 2003, Derry, Paulsen et al. 2007), whose subunit plasticity is implicated in biphasic neuronal actions (Simeone, Donevan et al. 2003) and paradoxical emotional responses to therapeutic drugs during female endocrine transitions (Andreen, Nyberg et al. 2009). Although the neuroanatomic site of action for these paradoxical effects is not established, GABAA receptor activation in the nucleus accumbens has been shown to inhibit reward and induce anxiolysis (Lopes, da Cunha et al. 2007, Koo, Lobo et al. 2014). Therefore, our focus was on the potential mediation of effects of fluoxetine by accumbal GABAA receptors.

\section{MATERIALS AND METHODS}

Animals. Female hamsters (Mesocricetus auratus) of the Crl:LVG(SYR) strain (Charles River Labs, Kingston, NY) were purchased for use at Weill Cornell Medical College or purchased and bred in the Kleberg Laboratory Animal Research Facility (TAMU) for three generations. They were kept on a 14h:10h light-dark schedule (lights on at $0600 \mathrm{~h}$ ) at $23 \pm 3{ }^{\circ} \mathrm{C}$, and singly housed 2 weeks before testing. LabDiet 5001 (Purina, Richmond, IN) and tap water were provided ad libitum. Food intake was assessed by combining the weight of chow in the hopper and bedding at $1200 \mathrm{~h}$ to the nearest $0.1 \mathrm{~g}$. Behavioral testing and euthanasia for brain collection occurred between 1000h-1600h in a behavior room. One week before behavior testing, 20 mg/animal of test food, graham cracker (Nabisco, East Hanover, NJ), was provided daily. Food was removed from home cages $1.5 \mathrm{~h}$ before testing. Procedures were approved by the Institutional Animal Care and Use Committees.

Reward investigation/preference (RIP) test. Individuals were acclimated to test cages for 10 minutes. Reward (graham cracker) or blank (empty) cassettes were placed in food hoppers for 5 minutes. Cassettes were clear plastic containers of MiniDV camcorder videotape (Maxell, Woodland Park, NJ). Time spent investigating (i.e., sniffing, scratching, and biting) each cassette was assessed by a treatment-blind scorer. Increases in cumulative reward investigation and 
reward investigational preference (reward investigation / total investigation $\mathrm{x} 100$ ) provided indices of hedonic drive. The RIP test is responsive to chronic, but not acute, antidepressant treatment, and unresponsive to non-antidepressant drugs (Shannonhouse, Grater et al. 2015).

Anxiety-related feeding/exploration conflict (AFEC) test. Subjects were assessed as we have described previously (Shannonhouse, Fong et al. 2014, Shannonhouse, York et al. 2014, Shannonhouse, Grater et al. 2015). After transfer of a subject to test cages, graham cracker was presented overhead in a spring-loaded utility clamp. Latencies to sniff (approach) and bite (feed) test food were timed in test cages and 1-2 h after return to home cages. To account for nonmotivational (e.g., motoric) influences on the ability to locate food, test/home cage ratios for approaching and feeding were calculated. High feed latency in the test cage and a high feed latency ratio are indices anxiety. These indices are reduced by acute anxiolytic treatment and chronic, but not acute, antidepressant treatment, and not by non-anxiolytic treatment.

Accumbal microdissection. Brains were excised post mortem, frozen in isopentane on dry ice, and stored at $-80{ }^{\circ} \mathrm{C}$. They were later blocked, mounted on a freezing microtome stage, and sectioned at $150 \mu \mathrm{m}$ through the striatum. Tissue sections were placed on glass slides on a freezing plate and the ventral striatum containing the nucleus accumbens was dissected under a surgical microscope using 0.75 mm-diameter metal core punches (Ted Pella, Redding, CA).

RNA extraction. As we have described previously (Shannonhouse, Grater et al. 2015), tissue samples were homogenized in phenol, isoamyl alcohol, guanidinium isothiocyanate, and 2mercaptoethanol with 18-G needles fitted onto 1-cc syringes. Monophasic homogenates were separated into 2 layers with a 20\% volume of chloroform, followed by centrifugation. The aqueous phase was extracted twice using one volume of 5:1 phenol:chloroform ( $\mathrm{pH} 4.5)$, and once with one volume of chloroform, precipitated with isopropanol and centrifugation, and washed with 75\% ethanol. RNA quality was assessed by spectrophotometry.

Reverse transcription PCR. Reverse transcription was performed as described (Shannonhouse, Urbanski et al. 2014, Shannonhouse, York et al. 2014), using M-MLV reverse transcriptase (New England Biolabs, Ipswich, MA). PCR was performed using Taq 2X Master Mix (New England Biolabs) and primers listed in Table 1 with a hot start at $91^{\circ} \mathrm{C}$, denaturation at $94^{\circ} \mathrm{C}$ for 50s, and cycling at melting temperatures listed in Table 1 for 20s. Hybridization occurred at $60^{\circ} \mathrm{C}$ for 20 s, with extension at $72^{\circ} \mathrm{C}$ for 30 s using cycle numbers listed in Table 1 . Amplicons were visualized on agarose, $5 \mathrm{mM}$ sodium tetraborate gels and stained with ethidium bromide (ISC Bioexpress, Kaysville, UT). Band intensities were analyzed using Kodak 1D Image Analysis Software (Eastman Kodak, Rochester, NY). Data from genes of interest are means of triplicate or quadruplicate reactions normalized to the median. Standards were run in duplicate (Gapdh and Beta Actin primer set 2) or triplicate (Beta Actin primer set 1). The three standards were highly correlated with one another $\left(\mathrm{r}^{2}>0.9\right.$ for all pairings). Quantifications were normalized to means of the standards.

Acute brain slice preparation. On the day of electrophysiological recordings, coronal slices containing nucleus accumbens were prepared essentially as we have described previously (DuBois, Parrish et al. 2004, DuBois, Trzeciakowski et al. 2006). Hamsters were decapitated on postnatal day 42 or 63 . Brains were excised and cooled by immersion in $0-4^{\circ} \mathrm{C}$ artificial cerebral 
spinal fluid (ACSF) containing: $2 \mathrm{mM} \mathrm{KCl} ; 1 \mathrm{mM} \mathrm{MgCl}_{2}-6 \mathrm{H}_{2} \mathrm{O} ; 2 \mathrm{mM} \mathrm{MgSO}{ }_{4}-7 \mathrm{H}_{2} \mathrm{O} ; 1 \mathrm{mM}$ $\mathrm{CaCl}_{2} ; 1.25 \mathrm{mM} \mathrm{NaH} \mathrm{PO}_{4} ; 26 \mathrm{mM} \mathrm{NaHCO}_{3} ; 14 \mathrm{mM}$ D-glucose; $206 \mathrm{mM}$ sucrose; $0.8 \mathrm{mM}$ kynurenic acid; bubbled with 95/5\% $\mathrm{O}_{2} / \mathrm{CO}_{2}$; $\mathrm{pH}$ 7.4; 290-310 mosM. Brains were blocked and 300- $\mu \mathrm{m}$ slices were cut on a VibroSlice (Campden Instruments, Lafayette, IN) in the same solution. Slices were transferred to oxygenated $\left(95 / 5 \% \mathrm{O}_{2} / \mathrm{CO}_{2}\right)$ ACSF containing: $124 \mathrm{mM}$ $\mathrm{NaCl} ; 3$ mM KCl; 1.5 mM MgSO $; 2.4 \mathrm{mM} \mathrm{CaCl}_{2} ; 1.25$ mM NaH $\mathrm{PO}_{4} ; 10$ mM D-(+)-glucose; $26 \mathrm{mM} \mathrm{NaHCO}$; $\mathrm{pH} 7.4 ; 290-310$ mosM. They were gradually warmed to $\sim 32^{\circ} \mathrm{C}$, incubated for $\sim 30 \mathrm{~min}$, and then allowed to cool to $\sim 22^{\circ} \mathrm{C}$ prior to experimentation. Individual slices were transferred to a recording chamber, submerged using a slice anchor (Warner Instruments, Hamden, CT) and continuously perfused with the same solution during recordings.

Electrophysiology. Whole-cell patch-clamp techniques were used as described previously (DuBois, Parrish et al. 2004, DuBois, Trzeciakowski et al. 2006). Patch pipettes were pulled from glass capillary tubing (KG-33, 1.5 mm, o.d., Garner Glass, Claremont, CA) on a P-97 Flaming/Brown micropipette puller (Sutter Instr., Novato, CA) to resistances of 2-8 M $\Omega$. Pipettes were filled with solution containing: $130 \mathrm{mM} \mathrm{CsCl} ; 10 \mathrm{mM}$ EGTA; 2 mM MgCl2; 10 mM HEPES; 4 mM Mg-ATP; 0.1 mM GTP; pH 7.2 with CsOH; 295-300 mosM. Slices were visualized with Olympus BX50/51 WI upright microscopes (40X long working distance water immersion, differential interference contrast video enhanced optics). Neurons were recorded in the core of the nucleus accumbens (surrounding the anterior commissure) within the ventral striatum. It should be noted that $95 \%$ of striatal neurons are GABAergic medium spiny neurons (Durieux, Schiffmann et al. 2011). Resting membrane potential was -60 to $-70 \mathrm{mV}$. Neurons were voltage-clamped at $-60 \mathrm{mV}$ and recordings taken from pharmacologically isolated GABA mIPSCs from saline- or fluoxetine-treated hamsters. Tetrodotoxin $(0.5 \mu \mathrm{M}$, TTX) was used to block $\mathrm{Na}^{+}$channels and inhibit action potential-evoked release of neurotransmitter while $40 \mu \mathrm{M}$ D,L-2-amino-5-phosphonovaleric acid (APV), and $10 \mu \mathrm{M}$ 6,7-dinitroquinoxaline-2,3-dione (DNQX) were used to inhibit glutamate-mediated mEPSCs. GABAAR-mediated mIPSCs were defined by inhibition with $30 \mu \mathrm{M}$ bicuculline. The actions of acute fluoxetine application was tested for periods of several minutes with a pair of pipettes $(300 \mu \mathrm{m}$ i.d., glass tubing) under manual control. One pipette delivered bath solution to the recording environment and was displaced by the 2nd pipette for drug application. Drug delivery pipettes were positioned just above the slice over the recorded cell and bath solution or drug was delivered continually over the slice for a sufficient time to allow penetration of drug to the local neuronal environment or drug washout as required. Most drugs reached saturation at the recorded neuron within 2-4 min for cells near the slice surface (i.e., depth of $\sim 50-100 \mu \mathrm{m}$ ). Voltage-clamp current recordings were collected and digitized with a Multiclamp 700B amplifier and Digidata 1440A interface and pClamp 10 software (Molecular Devices, Sunnyvale CA). Capacitance (pF) was read from the potentiometer used to zero capacitance transients. Data were low-pass filtered (8 pole Bessel, Frequency Devices) at $1-5 \mathrm{kHz}$ and digitized at $0.5-20 \mathrm{kHz}$. Series resistance was continually monitored. All experiments were carried out at room temperature.

Miniature postsynaptic current data analysis. Off-line analysis of GABAergic mIPSC kinetic parameters was performed using Minianalysis 6.03 (Synaptosoft, Inc., Decatur, GA), Prism 5 (GraphPad, Inc., San Diego CA), and Microsoft EXCEL as previously described (DuBois, Parrish et al. 2004, DuBois, Trzeciakowski et al. 2006). The mIPSC characteristics of amplitude, frequency (inter-event interval), and decay time constants were determined and compared. 
Individual currents $\geq 15$ pA could be clearly distinguished above baseline noise in the 3-4 min current traces collected from individual neurons. Event frequency was determined from the mean inter-event interval, while event peak amplitude was estimated as the absolute difference between the preceding baseline and maxima of the current. For mIPSC decay analysis, low noise traces and non-overlapping events were used to generate an ensemble average mIPSC by aligning the rising phase, and the 10-90\% decay phase of this average for each neuron which was fitted with a biexponential function: $y(t)=A_{1} \exp \left(-t / \tau_{1}\right)+A_{2} \exp \left(-t / \tau_{2}\right)+A_{s}(1)$ where $A_{1}$ and $A_{2}$ are the fraction of the fast and slow decay components, respectively, $A_{s}$ is the steady-state current, and $\tau_{1}$ and $\tau_{2}$ are the fast and slow time constants, respectively. Previously we found that mIPSC ensemble decay data under similar conditions gave a significantly better fit with two time constants relative to a fit with a single time constant (DuBois, Parrish et al. 2004).

Drugs and chemicals. Fluoxetine-HCl (Sigma, St. Louis, MO) was dissolved in drinking water at $0.17 \mathrm{mg} / \mathrm{ml}$. This concentration was designed to deliver $10 \mathrm{mg} / \mathrm{kg} / \mathrm{day}$, based on our previous work (Shannonhouse, Fong et al. 2014, Shannonhouse, York et al. 2014). To eliminate differences in the onset of initial treatment, subjects were injected with fluoxetine $(10 \mathrm{mg} / \mathrm{kg}$, ip) dissolved in $0.9 \%$ saline at $1200 \mathrm{~h}$ on day 1 , and behaviors were assessed at $1300 \mathrm{~h}$. The drug were then added to the drinking water at $1800 \mathrm{~h}$ on day 1 , and replaced every three days. Behaviors of adults were assessed weekly thereafter because fluoxetine was expected to improve performances in the RIP and AFEC tests only after chronic treatment. Because adolescents exhibited markedly elevated paradoxical behavioral responses to fluoxetine on day1, an additional day of testing was inserted on day 3 for higher resolution analyses. D,L-AP5 and TTX were purchased from Tocris. Kynurenic acid and DNQX were purchased from Sigma.

Statistical analyses. Two-way ANOVA and Bonferonni's post-hoc t-test (behavior, RT-PCR) and the Kolmogorov-Smirnov test and Student's $t$-test (electrophysiology) were performed using InStat 3.10 or Prism 5.04 (GraphPad, San Diego, CA).

\section{RESULTS}

\section{Effects of fluoxetine in the reward investigational preference test}

Adolescent fluoxetine (relative to vehicle). Fluoxetine treatment ( 10 mg/kg/day) beginning on postnatal day 42 (i.e., puberty) reduced the time spent investigating the reward cassette for one week, and failed to increase it for 3 weeks (Fig. 1a: drug $F_{1,60}=27.19, p<0.001$; age $\mathrm{F}_{4,60}=0.2, \mathrm{p}=0.936$; drug $\mathrm{x}$ age $\mathrm{F}_{4,60}=0.83, \mathrm{p}=0.513$ ). It did not alter blank cassette investigation (Fig. 1b). Fluoxetine also initially reduced reward investigational preference, and failed to increase it at any point assessed (Fig. 1c: drug $F_{1,60}=16.88$, $p<0.001$; age $F_{4,60}=4.44$, $\mathrm{p}=0.003$; drug $\mathrm{x}$ age $\mathrm{F}_{4,60}=1.95, \mathrm{p}=0.114$ ). These results suggest that initial fluoxetine treatment induced anhedonia at puberty and treatment resistance thereafter.

Adult fluoxetine (relative to vehicle). Fluoxetine treatment, which began on postnatal day 63, gradually improved reward investigation (Fig. $1 \mathrm{~d}$ : drug $\mathrm{F}_{1,48}=9.13$, $\mathrm{p}=0.004$; age $\mathrm{F}_{3,48}=$ $0.95, p=0.425$; drug $x$ age $F_{3,48}=1.08, p=0.367$ ). It did not alter blank investigation (Fig. 1e) or investigational preference (Fig. 1f). These results suggest that fluoxetine treatment gradually improved hedonic drive in adults. 


\section{Effects of fluoxetine in the anxiety-related feeding/exploration conflict test.}

Adolescent fluoxetine (relative to vehicle). Fluoxetine treatment ( 10 mg/kg/day) initially elevated test cage feed latency, and failed to reduce it within three weeks (Fig. 2a: drug $\mathrm{F}_{1,60}=$ 32.34, $\mathrm{p}<0.001$; age $\mathrm{F}_{4,60}=22.77, \mathrm{p}<0.001$; drug $\mathrm{x}$ age $\mathrm{F}_{4,60}=16.60, \mathrm{p}<0.001$ ). It transiently elevated home cage feed latency (Fig. $2 \mathrm{~b}$ : drug $\mathrm{F}_{1,60}=1.70, \mathrm{p}=0.198$; age $\mathrm{F}_{4,60}=4.48, \mathrm{p}=$ 0.003; drug $\mathrm{x}$ age $\mathrm{F}_{4,60}=5.25, \mathrm{p}=0.001$ ). It increased the feed latency ratio for one week, and failed to improve it afterward (Fig. 2c: drug $F_{1,60}=21.41, p<0.001$; age $F_{4,60}=6.52, p<0.001$; drug $\mathrm{x}$ age $\mathrm{F}_{4,60}=2.67, \mathrm{p}=0.041$ ). Indicating modest effects on motoric behavior, adolescent fluoxetine increased test cage approach latency for one week (Fig. 2d: drug $\mathrm{F}_{1,60}=35.80$, $\mathrm{p}<$ 0.001; age $\mathrm{F}_{4,60}=14.16, \mathrm{p}<0.001$; drug $\mathrm{x}$ age $\mathrm{F}_{4,60}=4.36, \mathrm{p}=0.004$ ), and elevated home cage approach latency on day one (Fig. 2e: drug $F_{1,60}=6.72$, $p=0.119$; age $F_{4,60}=3.72$, $p=0.009$; drug $x$ age $F_{4,60}=2.88, p=0.030$ ), but did not alter the approach latency ratio (Fig. $2 \mathrm{f}$ ). These results suggest that fluoxetine induced anxiety at puberty and treatment resistance thereafter.

Adult fluoxetine (relative to vehicle). Fluoxetine increased test cage feed latency on the first day, and reduced after three weeks (Fig. 2g: drug $F_{1,48}=2.15, p=0.149$; age $F_{3,48}=4.76, p$ $=0.006$; drug $x$ age $F_{3,48}=4.41, p=0.008$ ). It did not alter home cage feed latency (Fig. $2 \mathrm{~h}$ ), and elevated the feed latency ratio before reducing it (Fig. 2i: drug $\mathrm{F}_{1,48}=0.03, \mathrm{p}=0.871$; age $\mathrm{F}_{3,48}=$ 4.15, $\mathrm{p}=0.011$; drug $\mathrm{x}$ age $\mathrm{F}_{3,48}=9.60, \mathrm{p}<0.001$ ). Consistent with no detectable motoric effects, fluoxetine did not alter test cage approach latency (Fig. 2j), home cage approach latency (Fig. 2k), or the approach latency ratio (Fig. 2l). These results suggest that fluoxetine transiently elevated anxiety before gradually improving it.

Adolescents (relative to adults). Fluoxetine initially exerted greater test cage feed latency in adolescents than in adults (Flu effects in Fig. 2a and Fig. 2g: drug $\mathrm{F}_{1,48}=3.79, \mathrm{p}=0.057$; age $\mathrm{F}_{3,48}=24.77 ; \mathrm{p}<0.001$; drug $\mathrm{x}$ age $\mathrm{F}_{3,48}=2.83 ; \mathrm{p}=0.048$ ). It did not exert different effects on home cage feed latency (Flu effects in Fig. 2bB and Fig. 2h) or the feed latency ratio (Flu effects in Fig. 2c and Fig. 2i). These results suggest that fluoxetine induced anxiety with greater magnitude and duration in adolescents than in adults.

\section{Effects of fluoxetine on food intake}

We have shown previously that fluoxetine is anorexigenic (Wellman, Jones et al. 2003) and that reductions in food intake by deprivation or social manipulation are associated with the worsening of motivated behaviors in hamsters (Shannonhouse, Fong et al. 2014, Shannonhouse, York et al. 2014, Shannonhouse, Grater et al. 2015). Therefore, we assessed whether anorexigenic effects of fluoxetine caused the behavioral deficits described above. Although adolescent fluoxetine reduced food intake for three weeks (Fig. 3a: drug $F_{1,36}=34.06, p<0.001$; age $\mathrm{F}_{2,36}=15.60 ; \mathrm{p}<0.001$; drug $\mathrm{x}$ age $\mathrm{F}_{2,36}=0.49 ; \mathrm{p}=0.617$ ), it induced anhedonia and anxiety for only one week (see Figs. 1a, 1c, 2a, and 2c). In adults, fluoxetine inhibited food intake on days 3-7 (Fig. 3b: drug $F_{1,40}=5.54, p=0.024$; age $F_{3,40}=4.97 ; p=0.005$; drug $x$ age $F_{3,40}=$ $1.61 ; \mathrm{p}=0.202$ ), but anxious behavior was already worsened on day 1 (see Figs. 1d, 1f, 2g, and 2i). These findings do not rule out a partial contribution of hypophagia to behavioral changes in the RIP and AFEC tests, but they suggest that it was not the sole contributor.

\section{Acute effects of fluoxetine on accumbal mRNA levels at puberty or adulthood}

Fluoxetine (relative to vehicle) and GABAA receptor subunit $m R N A s$. Fluoxetine reduced GABAA receptor subunit $\alpha 1$ (Gabra1) mRNA levels at puberty (Fig. 4a: drug $\mathrm{F}_{1,18}=4.92, \mathrm{p}=$ 0.040 ; age $\mathrm{F}_{1,18}=39.65, \mathrm{p}<0.001$; drug $\mathrm{x}$ age $\left.\mathrm{F}_{1,18}=0.02, \mathrm{p}=0.901\right)$. It decreased Gabra2 
mRNA levels in adults (Fig. 4b: drug $\mathrm{F}_{1,18}=12.20, \mathrm{p}=0.003$; age $\mathrm{F}_{1,18}=70.93$, $\mathrm{p}<0.001$; drug $\mathrm{x}$ age $\left.\mathrm{F}_{1,18}=0.66, \mathrm{p}=0.429\right)$. There were no changes in Gabra3 mRNA levels (Fig. 4c). Gabra4 mRNA levels were also unaltered by fluoxetine (Fig. $4 \mathrm{~d}$ : drug $\mathrm{F}_{1,18}=1.39, \mathrm{p}=0.253$; age $\mathrm{F}_{1,18}=$ 5.57, $\mathrm{p}=0.030$; drug $\mathrm{x}$ age $\left.\mathrm{F}_{1,18}=0.25, \mathrm{p}=0.624\right)$. Fluoxetine reduced Gabra5 mRNA levels at puberty (Fig. 4e: drug $\mathrm{F}_{1,18}=4.21, \mathrm{p}=0.055$; age $\mathrm{F}_{1,18}<0.01, \mathrm{p}=0.959$; drug $\mathrm{x}$ age $\mathrm{F}_{1,18}=0.10$, $\mathrm{p}=0.756$ ). Fluoxetine did not alter Gabra6 mRNA levels (Fig. 4f) or Gabrb1 mRNA levels (Fig. 4g: drug $\mathrm{F}_{1,18}=0.58, \mathrm{p}=0.457$; age $\mathrm{F}_{1,18}=36.39$, $\mathrm{p}<0.001$; drug $\mathrm{x}$ age $\mathrm{F}_{1,18}=0.36, \mathrm{p}=$ 0.557). It decreased adult Gabrb2 mRNA levels (Fig. 4h: drug $\mathrm{F}_{1,18}=4.24, \mathrm{p}=0.055$; age $\mathrm{F}_{1,18}=$ 22.59, $\mathrm{p}<0.001$; drug $\mathrm{x}$ age $\mathrm{F}_{1,18}=1.50, \mathrm{p}=0.238$ ). Fluoxetine did not alter Gabrg1 mRNA levels (Fig. 4i: drug $\mathrm{F}_{1,18}=1.71, \mathrm{p}=0.208$; age $\mathrm{F}_{1,18}=11.19, \mathrm{p}=0.004$; drug $\mathrm{x}$ age $\mathrm{F}_{1,18}=0.74$, $\mathrm{p}=0.401$ ) or Gabrg2 mRNA levels (Fig. 4j: drug $\mathrm{F}_{1,18}=2.64, \mathrm{p}=0.123$; age $\mathrm{F}_{1,18}=12.64, \mathrm{p}=$ 0.002 ; drug $\mathrm{x}$ age $\left.\mathrm{F}_{1,18}=2.28, \mathrm{p}=0.150\right)$. Fluoxetine lowered Gabrd mRNA levels in adolescents (Fig. 4k: drug $\mathrm{F}_{1,18}=4.02$, $\mathrm{p}=0.060$; age $\mathrm{F}_{1,18}=29.43, \mathrm{p}<0.001$; drug $\mathrm{x}$ age $\mathrm{F}_{1,18}=$ 0.39, $\mathrm{p}=0.538)$.

Puberty (relative to adulthood) and GABAA receptor subunit mRNAs levels. Pubescent hamsters exhibited lower mRNA levels of GABAA receptor subunits Gabra1, Gabra2, Gabra4, Gabrb1, Gabrb2, Gabrg1, Gabrg2, and Gabrd (see the subsection above for statistics).

Fluoxetine (relative to vehicle) and accumbal GABAergic and motivation-related $m R N A s$. The 67-kDa glutamic acid decarboxylase (Gad67) mRNA levels were lower in adolescents, and they not altered by fluoxetine (Fig. 4l: drug $\mathrm{F}_{1,18}=0.78, \mathrm{p}=0.387$; age $\mathrm{F}_{1,18}=$ 14.47, $\mathrm{p}=0.001$; drug $\mathrm{x}$ age $\mathrm{F}_{1,18}=0.96, \mathrm{p}=0.341$ ). Fluoxetine decreased brain-derived neurotrophic factor (Bdnf) mRNA levels at puberty, and adults had higher levels (Fig. 4m: drug $\mathrm{F}_{1,18}=0.76, \mathrm{p}=0.396$; age $\mathrm{F}_{1,18}=6.40, \mathrm{p}=0.021$; drug $\mathrm{x}$ age $\mathrm{F}_{1,18}=1.68, \mathrm{p}=0.212$ ). Fluoxetine decreased cAMP response element-binding protein 1 (Creb1) mRNA levels overall, and adults had higher levels (Fig. 4n: drug $\mathrm{F}_{1,18}=9.87, \mathrm{p}=0.007$; age $\mathrm{F}_{1,18}=21.42$, $\mathrm{p}<0.001$; drug $\mathrm{x}$ age $\left.\mathrm{F}_{1,18}=5.37, \mathrm{p}=0.035\right)$. Fluoxetine decreased $\triangle F o s B$ mRNA levels overall, and adults had higher levels (Fig. 4o: drug $\mathrm{F}_{1,18}=4.95, \mathrm{p}=0.042$; age $\mathrm{F}_{1,18}=15.86, \mathrm{p}=0.001$; drug $\mathrm{x}$ age $\mathrm{F}_{1,18}=0.44$, $\mathrm{p}=0.517$ ). Fluoxetine decreased Fos $B$ mRNA levels overall, and adults had higher levels (Fig. 4p: drug $\mathrm{F}_{1,18}=15.23, \mathrm{p}=0.001$; age $\mathrm{F}_{1,18}=31.77, \mathrm{p}<0.001$; drug $\mathrm{x}$ age $\mathrm{F}_{1,18}=1.74, \mathrm{p}=0.207$ ).

\section{Acute effects of fluoxetine on accumbal GABA release at puberty or adulthood}

Fluoxetine bath-applied to adult accumbal slices. Miniature inhibitory postsynaptic currents (mIPSCs) that are spontaneous, asynchronous, and mediated by GABAA receptors were assessed using whole-cell patch clamping of accumbal neurons in coronal forebrain slices. Relative to baseline (Fig. 5a), fluoxetine at $10 \mu \mathrm{M}$ (Fig. 5b) increased the apparent mIPSC amplitude, but not its frequency, assessed in individual traces. Fluoxetine at $1 \mathrm{mM}$ (Fig. 5c) increased the apparent mIPSC amplitude and frequency.

Acute fluoxetine in vivo - individual traces. Pubescent (postnatal day 42) and adult (postnatal day 63) hamsters were injected with fluoxetine (0 or $10 \mathrm{mg} / \mathrm{kg}$, ip) 30 minutes before euthanasia, and GABAA receptor mIPSCs were recorded. Relative to vehicle (Fig. 5d), fluoxetine at puberty (Fig. 5e) appeared to increase the mIPSC amplitude and frequency, respectively. Relative to vehicle (Fig. 5f), fluoxetine during adulthood did not appear to alter amplitude or frequency (Fig. 5g). Bi-exponential function fits of mIPSC ensemble averages showed no differences in postsynaptic decay kinetic time constants, $\tau_{1}$ or $\tau_{2}$ in either age group (data not shown).

Acute fluoxetine (relative to vehicle) in vivo - cumulative probability plots. Kolmogorov- 
Smirnov analysis confirmed that pubescent fluoxetine treatment increased mIPSC amplitude (Fig. 6a: $\mathrm{p}<0.010$ ) and frequency (Fig. 6b: $\mathrm{p}<0.010$; vehicle $=2448$ events, $\mathrm{n}=16$ neurons; fluoxetine $=2975$ events, $\mathrm{n}=14$ neurons). Adult fluoxetine treatment decreased the mIPSC amplitude (Fig. 6c: $\mathrm{p}<0.010$ ) without altering its frequency (Fig. 6d: vehicle $=2066$ events, $\mathrm{n}=$ 12 neurons; fluoxetine $=2730$ events, $n=16$ neurons). Student's $t$-test analysis of the effects of fluoxetine on mean mIPSC amplitude further confirmed the enhancement at puberty (vehicle, $41.4 \pm 1.8 \mathrm{pA}$; fluoxetine, $47.5 \pm 2.2 \mathrm{pA}$; $\mathrm{p}<0.050$ ), but not the attenuation in adults. After fluoxetine treatment, adolescents exhibited lower mIPSC amplitude than did adults (Fig. 6e: $\mathrm{p}<$ 0.010) with no difference in the frequency (Fig. 6f). After vehicle treatment, adolescents exhibited lower mIPSC amplitude than did adults (Fig. 6g: $\mathrm{p}<0.010$ ) with no difference in the frequency (Fig. 6h.

\section{DISCUSSION}

We have taken four steps toward understanding adverse effects of antidepressants on the adolescent brain. First, we have shown that initial fluoxetine treatment without trauma or discontinuation worsened anhedonic behavior in adolescent female hamsters. Second, we have found that accumbal GABAA receptor signaling, a putative anhedonic signal (Koo, Lobo et al. 2014), was elevated by fluoxetine treatment in pubescent hamsters and reduced by it in adult hamsters. Third, we have shown quantitative differences between the fluoxetine-induced anxiety of adolescents and that of adults. Fourth, we are among the first to use a female model in this area of research.

Fluoxetine treatment at puberty suppressed reward investigation and reward investigational preference. The worsening of these indices of anhedonia persisted for one week, and was resistant to treatment in the following two-week period. By contrast, fluoxetine treatment of adults did not suppress behavioral responses to reward, but gradually improved them. The nucleus accumbens is a likely neural substrate for fluoxetine-induced anhedonia because it is a crucial component of reward responses. Accumbal GABAA receptors have been implicated in adolescent reward sensitivity (Mishra and Chergui 2013), and they inhibit rewardrelated dopamine release (Schulte, Callado et al. 2000). In addition, alterations in GABAA receptor signaling are associated with mood disorders (Fatemi, Folsom et al. 2013).

Interestingly, serotonergic signaling, a target of fluoxetine, also inhibits accumbal dopamine release with potential involvement of GABAA receptors (Guan and McBride 1989). Additionally, fluoxetine allosterically modulates GABAA receptors in a biphasic manner (Tunnicliff, Schindler et al. 1999, Robinson, Drafts et al. 2003, Derry, Paulsen et al. 2007). Specifically, low fluoxetine concentrations enhance sub-maximal GABA-stimulated chloride uptake in vitro. In contrast, high fluoxetine concentrations attenuate it, as well as agonist binding to GABAA receptors (Tunnicliff, Schindler et al. 1999). Unfortunately, age and sex differences on GABAergic signaling have not been studied extensively.

Anhedonia can be resolved into appetitive, consummatory, decisional, and motivational components (Smith, Berridge et al. 2011, Treadway and Zald 2011). We have reported that the experimental conditions used in the present study to promote emotional lability in adult hamsters, as well as various treatments (e.g., antidepressant, anxiolytic, and high-fat feeding) that modulate it, failed to alter appetite (Morgan, Urbanski et al. 2003, Shannonhouse, Fong et al. 2014, Shannonhouse, York et al. 2014). In addition, the use of plastic cassettes to prevent access 
to the test food in the RIP test helps eliminate considerations of appetitive anhedonia (e.g., decreased cheek pouching of food reward) and consummatory anhedonia (e.g., decreased ingestion of food reward). The lack of a requirement for hamsters to use reward information for decision making eliminated consideration of decisional anhedonia. It can, therefore, be deduced that the RIP test assesses motivational anhedonia (i.e., decreased effort in attempting to access food reward).

Initial fluoxetine treatment also markedly increased the latency of adolescent hamsters to eat highly palatable food under anxiogenic conditions, even when this behavior was normalized to the modestly elevated feed latency in non-anxiogenic conditions. Fluoxetine-induced anxiety persisted for one week and was resistant to continuous treatment into adulthood. Similar treatment beginning in adulthood initially increased anxiety, but gradually improved it. Importantly, fluoxetine-induced anxiety was more robust and persistent during adolescence than adulthood. Our findings are consistent with those of others showing transient anxiogenic responses in adult mammals to drugs that stimulate serotonergic signaling (Spigset 1999, Arrant, Coburn et al. 2013). Interestingly, acute fluoxetine treatment reduces accumbal dopamine release (Ichikawa and Meltzer 1995), and fluoxetine-induced anxiety can be attenuated by dopamine receptor activation (Belzung, Le Guisquet et al. 2001). Thus, reduced dopamine release potentially mediated fluoxetine-induced anxiety.

Our finding that fluoxetine was anorexigenic in hamsters might be used to argue that hypophagia caused the reduction in motivation to investigate food reward or eat it in an anxiogenic environment. The collective findings, however, do not support this argument because impairments in motivated behaviors and food intake were dissociable. Specifically, anorexigenic effects in adolescent hamsters persisted for three weeks, but the indices of motivational pathology lasted for only one week. Additionally, hypophagia in adult hamsters occurred between days three and seven of fluoxetine treatment, but there was no reward deficit at any time point assessed, and anxiogenesis occurred on day one and dissipated by day seven. It is also important to note that hamsters are unusual insofar as consummatory and appetitive behaviors are highly dissociable. For example, food deprivation does not induce compensatory hyperphagia in hamsters, but increases cheek pouching and hoarding of food to reflect an increase in appetite (Phillips, Robinson et al. 1989). Therefore, reduced consumption of moderately palatable chow does not necessarily indicate reduced appetite for the highly palatable test food. In support of this point, we have reported that disruption of the motivational state of hamsters did not alter appetitive behaviors in the AFEC test (Shannonhouse, Fong et al. 2014, Shannonhouse, York et al. 2014).

The argument for the reduced consummatory drive worsening motivated behavior is also weakened by the observation that elevated feed latency in home cages persisted for only one day in adolescents. A nonspecific decrease in food appetite would be expected to increase home cage feed latency throughout the study, as fluoxetine reduced chow consumption chronically in adolescents. We have also found that treatment with the tricyclic antidepressant, desipramine, worsened motivated behavior in pubescent, but not adult, female hamsters without altering food intake (unpublished data).

There were two patterns in accumbal molecular responses to fluoxetine. First, there were lower mRNA levels for eight GABAA receptor subunits and for GABA-synthesizing GAD67 at puberty, relative to adulthood, which suggested low GABAergic tone. Second, fluoxetine caused age-dependent reductions in the mRNA levels of other relevant genes. Fluoxetine decreased mRNA levels of the $\alpha 1, \alpha 5$, and $\delta$ subunits and BDNF at puberty, and it decreased $\alpha 2$ and $\beta 2$ 
mRNA levels in adults. GABAA receptors have been shown to be less sensitive to fluoxetine when the $\alpha 5$, but not $\beta$ or $\gamma$, subunit was co-expressed with $\alpha 1$ subunits (Robinson, Drafts et al. 2003). Thus, the $\alpha 5$ reduction likely mediated stimulatory effects of fluoxetine. In addition, the fluoxetine-induced reduction of accumbal BDNF signaling potentially contributed to anhedonia and anxiety during adolescence (Bahi, Boyer et al. 2008, Ravenelle, Byrnes et al. 2013). Although the fluoxetine-induced reduction of CREB signaling potentially reflected anxiogenesis in adults (Barrot, Wallace et al. 2005), the absence of a significant reduction in adolescents suggests different etiologies. The overall reductions of $\triangle$ FosB and FosB mRNA levels suggest that fluoxetine reduced reward signaling acutely (Hedges, Chakravarty et al. 2009, Pitchers, Vialou et al. 2013).

Electrophysiological analysis confirmed that baseline GABAergic tone was lower at puberty than adulthood, due to the lower mIPSC amplitude. Moreover, fluoxetine likely potentiated GABA release at puberty, due to elevated mIPSC amplitude and frequency. In contrast, similar treatment of adults likely attenuated GABA release, due to lower mIPSC amplitude. Amplitude is influenced by postsynaptic receptor density, synaptic vesicle GABA content, and dendritic cable properties (Cherubini and Conti 2001). Frequency is related to synapse number and presynaptic GABA release (Kohara, Yasuda et al. 2007). Our results are consistent with the idea that fluoxetine acted rapidly on presynaptic and postsynaptic components to induce GABA release at puberty. The decrease in mIPSC amplitude in adults indicates that fluoxetine rapidly inhibited postsynaptic GABAA receptors without altering presynaptic GABA release.

Low and high concentrations of fluoxetine have been demonstrated to potentiate and attenuate, respectively, sub-maximal GABA-induced signaling through GABAA receptors in vitro (Tunnicliff, Schindler et al. 1999). Accordingly, we deduce from molecular and electrophysiological indices that low baseline GABAergic tone in pubescent hamsters promoted stimulatory effects of fluoxetine on accumbal GABAA receptors. Based on evidence that GABAA receptor activation inhibits drug reward (Koo, Lobo et al. 2014), the fluoxetine-induced increase in GABAergic signaling potentially contributed to anhedonic behavior. Conversely, high baseline GABAergic tone and fluoxetine-induced attenuation of GABAergic signaling in adults is consistent with the absence of anhedonic effects during initial treatment. Moreover, considering the biphasic capability of GABAA receptors, stimulatory effects of bath-applied fluoxetine on adult hamster brain slices could have resulted from low GABAergic tone, as GABA was not applied to the slices.

GABAA receptor activation in the nucleus accumbens has been shown to induce anxiolysis (Lopes, da Cunha et al. 2007), which helps explain the fluoxetine induction of anxiety in adulthood. It is also known that GABAergic signaling suppresses accumbal dopamine release (Schulte, Callado et al. 2000, Rahman and McBride 2002), and anxiolytic effects on behavior by modulation of dopamine D1 and D2 receptors has been shown to depend on accumbal D1 receptors (Ahmadi, Nasehi et al. 2013). Thus, the fluoxetine-induced potentiation of GABAergic signaling in adolescents could have exerted anxiogenic effects at puberty by altering different components of accumbal dopaminergic signaling.

In conclusion, we have developed a model of paradoxical emotional responses and antidepressant resistance using female hamsters treated with fluoxetine beginning at puberty. We have also taken early steps toward characterizing neurobiological underpinnings for the effects of fluoxetine, and our findings implicate accumbal GABAA receptor plasticity. The field would benefit from future studies that examine potential age and sex differences in behavioral and 
accumbal, including dopaminergic, responses to SSRIs and other classes of antidepressants. Widespread antidepressant use and the obscurity of underpinnings for deleterious actions and modest efficacy during adolescence contribute to the importance and urgency of this work.

\section{REFERENCES}

Ahmadi, H., M. Nasehi, P. Rostami and M. R. Zarrindast (2013). "Involvement of the nucleus accumbens shell dopaminergic system in prelimbic NMDA-induced anxiolytic-like behaviors." Neuropharmacology 71: 112-123.

Andreen, L., S. Nyberg, S. Turkmen, G. van Wingen, G. Fernandez and T. Backstrom (2009). "Sex steroid induced negative mood may be explained by the paradoxical effect mediated by GABAA modulators." Psychoneuroendocrinology 34(8): 1121-1132.

Arrant, A. E., E. Coburn, J. Jacobsen and C. M. Kuhn (2013). "Lower anxiogenic effects of serotonin agonists are associated with lower activation of amygdala and lateral orbital cortex in adolescent male rats." Neuropharmacology 73: 359-367.

Bahi, A., F. Boyer, V. Chandrasekar and J. L. Dreyer (2008). "Role of accumbens BDNF and TrkB in cocaine-induced psychomotor sensitization, conditioned-place preference, and reinstatement in rats." Psychopharmacology (Berl) 199(2): 169-182.

Barrot, M., D. L. Wallace, C. A. Bolanos, D. L. Graham, L. I. Perrotti, R. L. Neve, H. Chambliss, J. C. Yin and E. J. Nestler (2005). "Regulation of anxiety and initiation of sexual behavior by CREB in the nucleus accumbens." Proc Natl Acad Sci U S A 102(23): 8357-8362. Belzung, C., A. M. Le Guisquet, S. Barreau and F. Calatayud (2001). "An investigation of the mechanisms responsible for acute fluoxetine-induced anxiogenic-like effects in mice." Behav Pharmacol 12(3): 151-162.

Bouet, V., A. Klomp, T. Freret, M. Wylezinska-Arridge, J. Lopez-Tremoleda, F. Dauphin, M. Boulouard, J. Booij, W. Gsell and L. Reneman (2012). "Age-dependent effects of chronic fluoxetine treatment on the serotonergic system one week following treatment."

Psychopharmacology (Berl) 221(2): 329-339.

Bridge, J. A., S. Iyengar, C. B. Salary, R. P. Barbe, B. Birmaher, H. A. Pincus, L. Ren and D. A. Brent (2007). "Clinical response and risk for reported suicidal ideation and suicide attempts in pediatric antidepressant treatment: a meta-analysis of randomized controlled trials." JAMA 297(15): 1683-1696.

Cherubini, E. and F. Conti (2001). "Generating diversity at GABAergic synapses." Trends Neurosci 24(3): 155-162.

Cusin, C., M. Fava, J. D. Amsterdam, F. M. Quitkin, F. W. Reimherr, C. M. Beasley, Jr., J. F. Rosenbaum and R. H. Perlis (2007). "Early symptomatic worsening during treatment with fluoxetine in major depressive disorder: prevalence and implications." $\underline{\mathrm{J} \text { Clin Psychiatry 68(1): }}$ 52-57.

de Jong, T. R., L. J. Snaphaan, T. Pattij, J. G. Veening, M. D. Waldinger, A. R. Cools and B. Olivier (2006). "Effects of chronic treatment with fluvoxamine and paroxetine during adolescence on serotonin-related behavior in adult male rats." Eur Neuropsychopharmacol 16(1): 39-48.

Derry, J. M., I. M. Paulsen, M. Davies and S. M. Dunn (2007). "A single point mutation of the 
GABA(A) receptor alpha5-subunit confers fluoxetine sensitivity." Neuropharmacology 52(2): 497-505.

DuBois, D. W., A. R. Parrish, J. P. Trzeciakowski and G. D. Frye (2004). "Binge ethanol exposure delays development of GABAergic miniature postsynaptic currents in septal neurons." Brain Res Dev Brain Res 152(2): 199-212.

DuBois, D. W., J. P. Trzeciakowski, A. R. Parrish and G. D. Frye (2006). "GABAergic miniature postsynaptic currents in septal neurons show differential allosteric sensitivity after binge-like ethanol exposure." Brain Res 1089(1): 101-115.

Durieux, P. F., S. N. Schiffmann and A. de Kerchove d'Exaerde (2011). "Targeting neuronal populations of the striatum." Front Neuroanat 5: 40.

Fatemi, S. H., T. D. Folsom, R. J. Rooney and P. D. Thuras (2013). "Expression of GABAA alpha2-, beta1- and epsilon-receptors are altered significantly in the lateral cerebellum of subjects with schizophrenia, major depression and bipolar disorder." Transl Psychiatry 3: e303. Guan, X. M. and W. J. McBride (1989). "Serotonin microinfusion into the ventral tegmental area increases accumbens dopamine release." Brain Res Bull 23(6): 541-547.

Hedges, V. L., S. Chakravarty, E. J. Nestler and R. L. Meisel (2009). "Delta FosB overexpression in the nucleus accumbens enhances sexual reward in female Syrian hamsters." Genes Brain Behav 8(4): 442-449.

Homberg, J. R., J. D. Olivier, T. Blom, T. Arentsen, C. van Brunschot, P. Schipper, G. KorteBouws, G. van Luijtelaar and L. Reneman (2011). "Fluoxetine exerts age-dependent effects on behavior and amygdala neuroplasticity in the rat." PLoS One 6(1): e16646.

Ichikawa, J. and H. Y. Meltzer (1995). "Effect of antidepressants on striatal and accumbens extracellular dopamine levels." Eur J Pharmacol 281(3): 255-261.

Iniguez, S. D., L. F. Alcantara, B. L. Warren, L. M. Riggs, E. M. Parise, V. Vialou, K. N. Wright, G. Dayrit, S. J. Nieto, M. B. Wilkinson, M. K. Lobo, R. L. Neve, E. J. Nestler and C. A. Bolanos-Guzman (2014). "Fluoxetine exposure during adolescence alters responses to aversive stimuli in adulthood." J Neurosci 34(3): 1007-1021.

Iniguez, S. D., B. L. Warren and C. A. Bolanos-Guzman (2010). "Short- and long-term functional consequences of fluoxetine exposure during adolescence in male rats." Biol Psychiatry 67(11): 1057-1066.

Jick, H., J. A. Kaye and S. S. Jick (2004). "Antidepressants and the risk of suicidal behaviors." JAMA 292(3): 338-343.

Karanges, E., K. M. Li, C. Motbey, P. D. Callaghan, A. Katsifis and I. S. McGregor (2011). "Differential behavioural and neurochemical outcomes from chronic paroxetine treatment in adolescent and adult rats: a model of adverse antidepressant effects in human adolescents?" Int J Neuropsychopharmacol 14(4): 491-504.

Kohara, K., H. Yasuda, Y. Huang, N. Adachi, K. Sohya and T. Tsumoto (2007). "A local reduction in cortical GABAergic synapses after a loss of endogenous brain-derived neurotrophic factor, as revealed by single-cell gene knock-out method." J Neurosci 27(27): 7234-7244. Koo, J. W., M. K. Lobo, D. Chaudhury, B. Labonte, A. Friedman, E. Heller, C. J. Pena, M. H. Han and E. J. Nestler (2014). "Loss of BDNF signaling in D1R-expressing NAc neurons enhances morphine reward by reducing GABA inhibition." Neuropsychopharmacology 39(11): 2646-2653.

Kshama, D., H. J. Hrishikeshavan, R. Shanbhogue and U. S. Munonyedi (1990). "Modulation of baseline behavior in rats by putative serotonergic agents in three ethoexperimental paradigms." Behav Neural Biol 54(3): 234-253. 
Liu, J., J. C. Garza, J. Bronner, C. S. Kim, W. Zhang and X. Y. Lu (2010). "Acute administration of leptin produces anxiolytic-like effects: a comparison with fluoxetine." Psychopharmacology (Berl) 207(4): 535-545.

Lopes, A. P., I. C. da Cunha, S. M. Steffens, A. Ferraz, J. C. Vargas, T. C. de Lima, J. M. Neto, M. S. Faria and M. A. Paschoalini (2007). "GABAA and GABAB agonist microinjections into medial accumbens shell increase feeding and induce anxiolysis in an animal model of anxiety." Behav Brain Res 184(2): 142-149.

Mann, J. J., G. Emslie, R. J. Baldessarini, W. Beardslee, J. A. Fawcett, F. K. Goodwin, A. C. Leon, H. Y. Meltzer, N. D. Ryan, D. Shaffer and K. D. Wagner (2006). "ACNP Task Force report on SSRIs and suicidal behavior in youth." Neuropsychopharmacology 31(3): 473-492. Mishra, D. and K. Chergui (2013). "Ethanol inhibits excitatory neurotransmission in the nucleus accumbens of adolescent mice through GABAA and GABAB receptors." Addict Biol 18(4): 605-613.

Morgan, C., H. F. Urbanski, W. Fan, H. Akil and R. D. Cone (2003). "Pheromone-induced anorexia in male Syrian hamsters." Am J Physiol Endocrinol Metab 285(5): E1028-1038. Oh, J. E., B. Zupan, S. Gross and M. Toth (2009). "Paradoxical anxiogenic response of juvenile mice to fluoxetine." Neuropsychopharmacology 34(10): 2197-2207.

Phillips, J. H., A. Robinson and G. C. Davey (1989). "Food hoarding behaviour in the golden hamster (Mesocricetus auratus): effects of body weight loss and hoard-size discrimination." Q J Exp Psychol B 41(1): 33-47.

Pitchers, K. K., V. Vialou, E. J. Nestler, S. R. Laviolette, M. N. Lehman and L. M. Coolen (2013). "Natural and drug rewards act on common neural plasticity mechanisms with DeltaFosB as a key mediator." J Neurosci 33(8): 3434-3442.

Rahman, S. and W. J. McBride (2002). "Involvement of GABA and cholinergic receptors in the nucleus accumbens on feedback control of somatodendritic dopamine release in the ventral tegmental area." J Neurochem 80(4): 646-654.

Ravenelle, R., E. M. Byrnes, J. J. Byrnes, C. McInnis, J. H. Park and S. T. Donaldson (2013).

"Environmental enrichment effects on the neurobehavioral profile of selective outbred trait anxiety rats." Behav Brain Res 252: 49-57.

Robinson, R. T., B. C. Drafts and J. L. Fisher (2003). "Fluoxetine increases GABA(A) receptor activity through a novel modulatory site." J Pharmacol Exp Ther 304(3): 978-984.

Rynn, M., A. Puliafico, C. Heleniak, P. Rikhi, K. Ghalib and H. Vidair (2011). "Advances in pharmacotherapy for pediatric anxiety disorders." Depress Anxiety 28(1): 76-87.

Schatzberg, A. F., P. Haddad, E. M. Kaplan, M. Lejoyeux, J. F. Rosenbaum, A. H. Young and J. Zajecka (1997). "Possible biological mechanisms of the serotonin reuptake inhibitor discontinuation syndrome. Discontinuation Consensus Panel." J Clin Psychiatry 58 Suppl 7: 2327.

Schulte, D., L. F. Callado, C. Davidson, P. E. Phillips, N. Roewer, J. Schulte am Esch and J. A. Stamford (2000). "Propofol decreases stimulated dopamine release in the rat nucleus accumbens by a mechanism independent of dopamine D2, GABAA and NMDA receptors." Br J Anaesth 84(2): 250-253.

Shannonhouse, J. L., L. A. Fong, B. L. Clossen, R. E. Hairgrove, D. C. York, B. B. Walker, G. W. Hercules, L. M. Mertesdorf, M. Patel and C. Morgan (2014). "Female-biased anorexia and anxiety in the Syrian hamster." Physiol Behav 133: 141-151.

Shannonhouse, J. L., D. M. Grater, D. York, P. J. Wellman and C. Morgan (2015). "Sex differences in motivational responses to dietary fat in Syrian hamsters." Physiol Behav 147: 102- 
116.

Shannonhouse, J. L., H. F. Urbanski, S. L. Woo, L. A. Fong, S. D. Goddard, W. F. Lucas, E. R. Jones, C. Wu and C. Morgan (2014). "Aquaporin-11 control of testicular fertility markers in Syrian hamsters." Mol Cell Endocrinol 391(1-2): 1-9.

Shannonhouse, J. L., D. C. York and C. Morgan (2014). "A modified anxious behavior test for hamsters." J Neurosci Methods 221: 62-69.

Simeone, T. A., S. D. Donevan and J. M. Rho (2003). "Molecular biology and ontogeny of gamma-aminobutyric acid (GABA) receptors in the mammalian central nervous system." $\underline{\mathrm{J}}$ Child Neurol 18(1): 39-48; discussion 49.

Smith, K. S., K. C. Berridge and J. W. Aldridge (2011). "Disentangling pleasure from incentive salience and learning signals in brain reward circuitry." Proc Natl Acad Sci U S A 108(27):

E255-264.

Spigset, O. (1999). "Adverse reactions of selective serotonin reuptake inhibitors: reports from a spontaneous reporting system." Drug Saf 20(3): 277-287.

Treadway, M. T. and D. H. Zald (2011). "Reconsidering anhedonia in depression: lessons from translational neuroscience." Neurosci Biobehav Rev 35(3): 537-555.

Tunnicliff, G., N. L. Schindler, G. J. Crites, R. Goldenberg, A. Yochum and E. Malatynska (1999). "The GABA(A) receptor complex as a target for fluoxetine action." Neurochem Res 24(10): 1271-1276.

Wellman, P. J., S. L. Jones and D. K. Miller (2003). "Effects of preexposure to dexfenfluramine, phentermine, dexfenfluramine-phentermine, or fluoxetine on sibutramine-induced hypophagia in the adult rat." Pharmacol Biochem Behav 75(1): 103-114.

West, C. H., J. C. Ritchie and J. M. Weiss (2010). "Paroxetine-induced increase in activity of locus coeruleus neurons in adolescent rats: implication of a countertherapeutic effect of an antidepressant." Neuropsychopharmacology 35(8): 1653-1663. 


\section{FIGURE LEGENDS}

Figure 1. Fluoxetine worsened anhedonia during adolescence. Female hamsters $(n=7)$ were injected with Flu (0 or $10 \mathrm{mg} / \mathrm{kg}$, ip) at puberty (postnatal day 42) or adulthood (postnatal day 63), and assessed in the reward investigational preference (RIP) test $1 \mathrm{~h}$ later. Flu (0 or 0.17 $\mathrm{mg} / \mathrm{ml}$ ) was added to the drinking water $6 \mathrm{~h}$ later to provide $\sim 10 \mathrm{mg} / \mathrm{kg} / \mathrm{day}$, po. On test days, subjects investigated reward (graham cracker) and blank (empty) cassettes for 5 minutes after acclimation to test chambers. Cumulative times spent investigating reward and blank cassettes were measured, and reward investigational preference (reward investigation / total investigation x 100) was calculated. Adolescent fluoxetine treatment: (a) initially suppressed investigation of the reward cassette; (b) did not alter investigation of the blank cassette; and (c) initially suppressed investigational preference for the reward. Adult fluoxetine treatment: (d) gradually improved reward investigation; (e) did not alter blank investigation; and (f) and did not alter reward investigational preference. Means \pm SEM are shown: ${ }^{*} \mathrm{p}<0.050 ;{ }^{* *} \mathrm{p}<0.010$.

Figure 2. Fluoxetine worsened anxiety during adolescence. Female hamsters $(n=7)$ represented in Fig. 1 were first assessed in the anxiety-related feeding/exploration conflict (AFEC) test. Graham cracker was provided in a test chamber without acclimation. Intervals between presenting the test food and having it sniffed (approach latency) and bitten (feed latency) were timed in test cages and $1 \mathrm{~h}$ after return to home cages. Test/home cage ratios for approaching and feeding were calculated. Adolescent fluoxetine treatment: (a) initially elevated feed latency in the anxiogenic test cage; (b) initially elevated feed latency in the home cage; (c) initially elevated the feed latency ratio (test cage/home cage); (d) initially elevated latency to approach food in the test cage; (e) initially elevated approach latency in the home cage; and (f) did not alter the approach latency ratio. Adult fluoxetine treatment: (g) initially elevated, but gradually reduce, test cage feed latency; (h) did not alter home cage feed latency; (i) initially elevated, but gradually reduce, the feed latency ratio; (j) did not alter test cage approach latency; (k) did not alter home cage approach latency; and (l) did not alter the approach latency ratio. Means \pm SEM are shown: ${ }^{*} \mathrm{p}<0.050 ;{ }^{* *} \mathrm{p}<0.010$.

Figure 3. Fluoxetine induced hypophagia. Hamsters $(n=6-7)$ were injected with vehicle (Veh, $0.9 \%$ saline, ip) or fluoxetine (Flu, $10 \mathrm{mg} / \mathrm{kg}$, ip) at puberty (postnatal day 42) or adulthood (postnatal day 63). Fluoxetine treatment was continued by adding it to the drinking water $(0.17$ $\mathrm{mg} / \mathrm{ml}$ ) beginning at $1800 \mathrm{~h}$ on the day of injection to provide $\sim 10 \mathrm{mg} / \mathrm{kg} / \mathrm{day}$. (A) Adolescent fluoxetine treatment suppressed food intake throughout the experiment; (B) Adult fluoxetine treatment suppressed food intake between days 3 and 7. Means \pm SEM are shown: ${ }^{*} \mathrm{p}<0.050$; ${ }^{* *} \mathrm{p}<0.010$. Results are shown for 1 experiment.

Figure 4. Fluoxetine and age reduced accumbal mRNA levels related to GABAA receptor and reward signals. Female hamsters $(n=4-5)$ were injected with fluoxetine ( 0 or $10 \mathrm{mg} / \mathrm{kg}$, ip) at puberty (postnatal day 42) or adulthood (postnatal day 63). At $3 \mathrm{~h}$ post-injection, subjects were euthanized and accumbal samples were assessed by RT-PCR. (a) Fluoxetine reduced Gabra1 subunit mRNA levels during adolescence, and they were higher during adulthood. (b) Fluoxetine did not alter Gabra2 mRNA levels, and they were higher during adulthood. (c) Fluoxetine and age did not alter Gabra3 mRNA levels. (d) Fluoxetine and age did not alter Gabra4 mRNA levels, and they were higher during adulthood. (e) Fluoxetine reduced Gabra5 mRNA levels. (f) 
Fluoxetine or age did not alter Gabra6 mRNA levels. (g) Gabrb1 mRNA levels were unaltered by fluoxetine, and higher during adulthood. (h) Gabrb2 mRNA levels were reduced by fluoxetine in adults, and they were higher during adulthood. (i) Gabrg1 mRNA levels were unaltered by fluoxetine, and higher during adulthood. (j) Gabrg2 mRNA levels were unaltered by fluoxetine, and higher during adulthood. (k) Gabrd mRNA levels were reduced by adolescent fluoxetine treatment, and higher during adulthood. (l) Gad67 mRNA levels were unaltered by fluoxetine, and higher during adulthood. (m) Bdnf mRNA levels were reduced by fluoxetine at puberty. (n) Creb1 mRNA levels were reduced by fluoxetine during adulthood, and adults had higher levels. (o) $\triangle F o s B$ mRNA levels were reduced overall by fluoxetine, and higher in adults. (p) FosB mRNA levels were reduced by fluoxetine at puberty and during adulthood, and adults had higher levels. Means \pm SEM are shown. Relative to vehicle ${ }^{*} \mathrm{p}<0.050$; ${ }^{* *} \mathrm{p}<0.010$; Relative to adulthood: $\uparrow \mathrm{p}<0.050 ; \dagger \dagger \mathrm{p}<0.010$.

Figure 5. Fluoxetine modulated accumbal GABAA receptor currents (individual traces). ( $a$ c) Fluoxetine-induced accumbal GABAA receptor currents in adults in vitro. Coronal slices, containing nucleus accumbens, were taken from the brain of an adult female hamster. Relative to baseline conditions (a), bath application of fluoxetine at $10 \mu \mathrm{M}$ (b) or $1 \mathrm{mM}$ (c) increased the frequency (expressed as inter-event intervals) and amplitude of GABAA receptor miniature inhibitory postsynaptic currents (mIPSCs). (d-g) Age-related fluoxetine modulation of accumbal GABAA receptor current ex vivo. A female hamster was injected with fluoxetine (0 or $10 \mathrm{mg} / \mathrm{kg}$, ip) at puberty (d and e) or adulthood (f and g), euthanized at 30 minutes post-injection, and accumbal slices were assessed for GABAA receptor mIPSCs for 2-6 h post-injection. Relative to vehicle (d), fluoxetine (e) increased the frequency and amplitude of GABAA receptor mIPSCs during adolescence. Relative to vehicle (f), fluoxetine (g) decreased the mIPSC amplitude, but did not alter its frequency, during adulthood. Results are shown for representative animals.

Figure 6. Fluoxetine and age modulated accumbal GABAA receptor current (cumulative probability plots). Female hamsters ( $n=3,12-16$ cells per animal) were injected with fluoxetine (0 or $10 \mathrm{mg} / \mathrm{kg}$, ip) at puberty (postnatal day 42) or adulthood (postnatal day 63) 30 minutes before euthanasia and brain collection. Whole-cell patch clamp recordings were made at $-60 \mathrm{mV}$ in baths containing TTX, APV, and DNQX. Cumulative probability plots of GABAA receptor mIPSCs are shown. Differences were determined by the Kolmogorov-Smirnov test. Relative to vehicle (2975 events), fluoxetine (2448 events) at puberty increased mIPSc: (a) amplitude (p < 0.010); and (b) frequency ( $\mathrm{p}<0.050$ ). Relative to vehicle (2730 events), fluoxetine (2066 events) during adulthood: (c) decreased mIPSC amplitude ( $<<0.010)$; but (d) did not alter its frequency. Relative to adults, pubescent hamsters exhibited: (e) lower mIPSC amplitude ( $<0.010$ ); and (f) no difference in mIPSC frequency during fluoxetine treatment. Relative to adults, pubescent hamsters exhibited: (g) lower mIPSC amplitude ( $\mathrm{p}<0.010)$; and (h) no difference in mIPSC frequency during vehicle treatment. 
Fig. 1
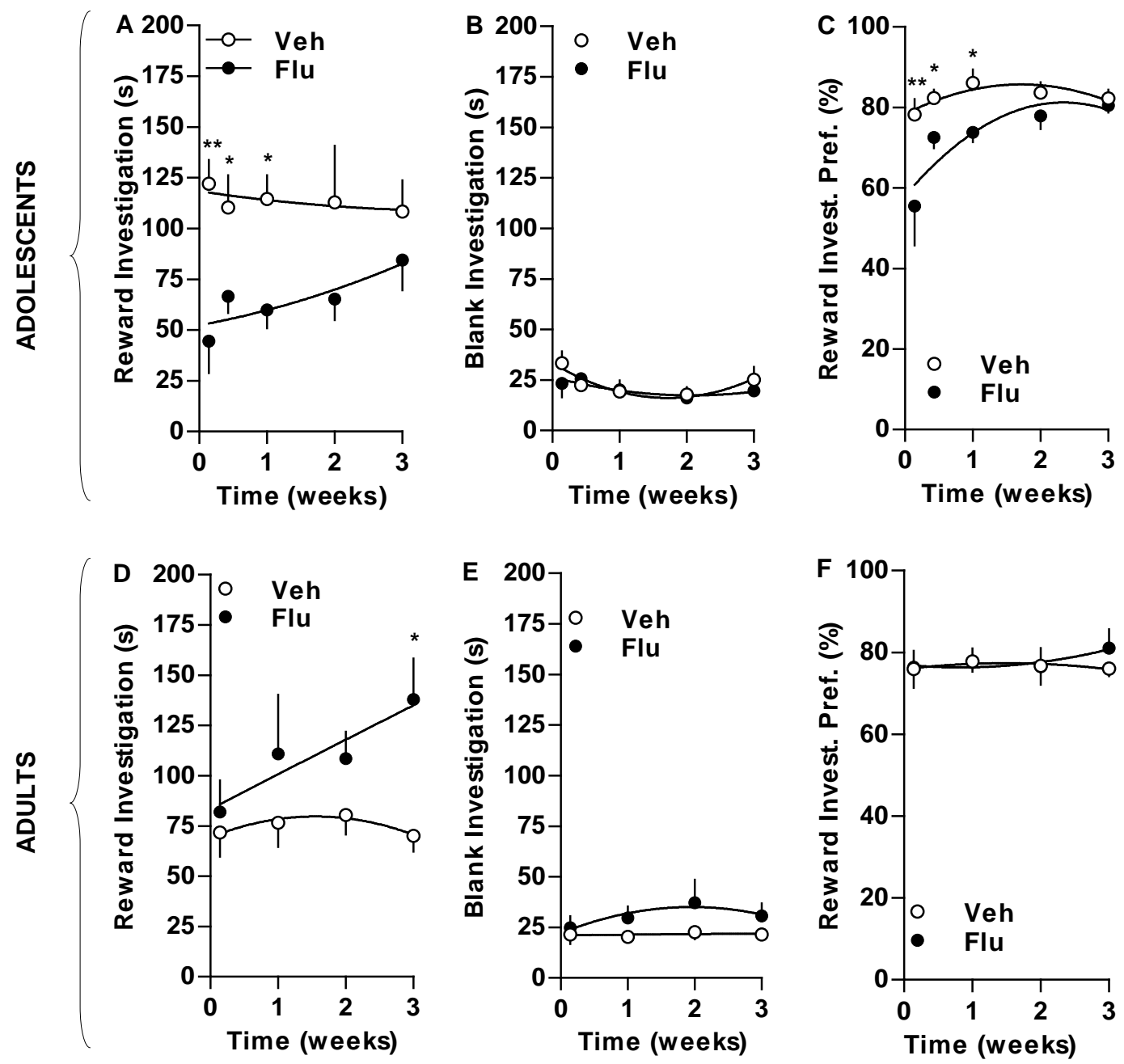
Fig. 2
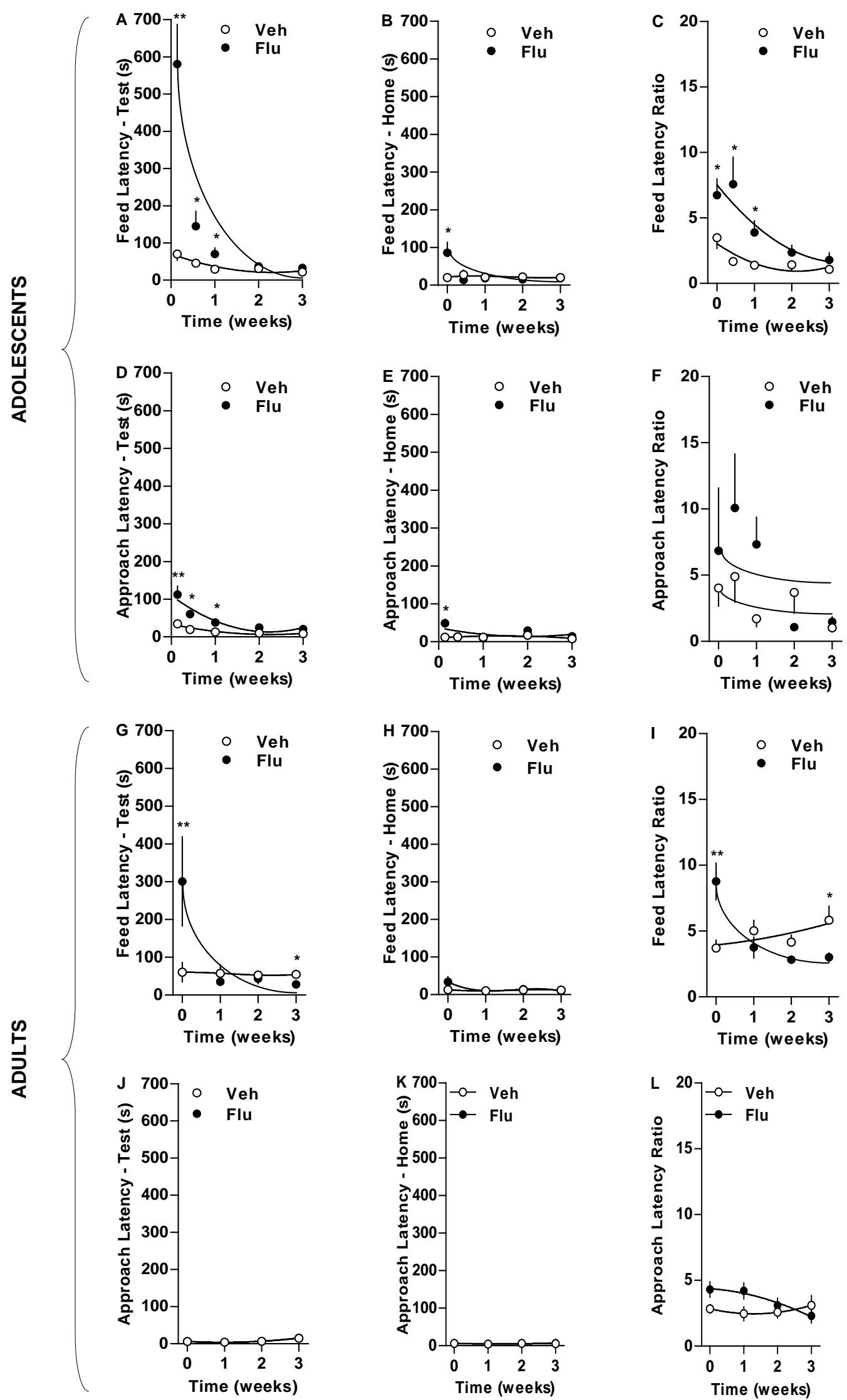
Fig. 3
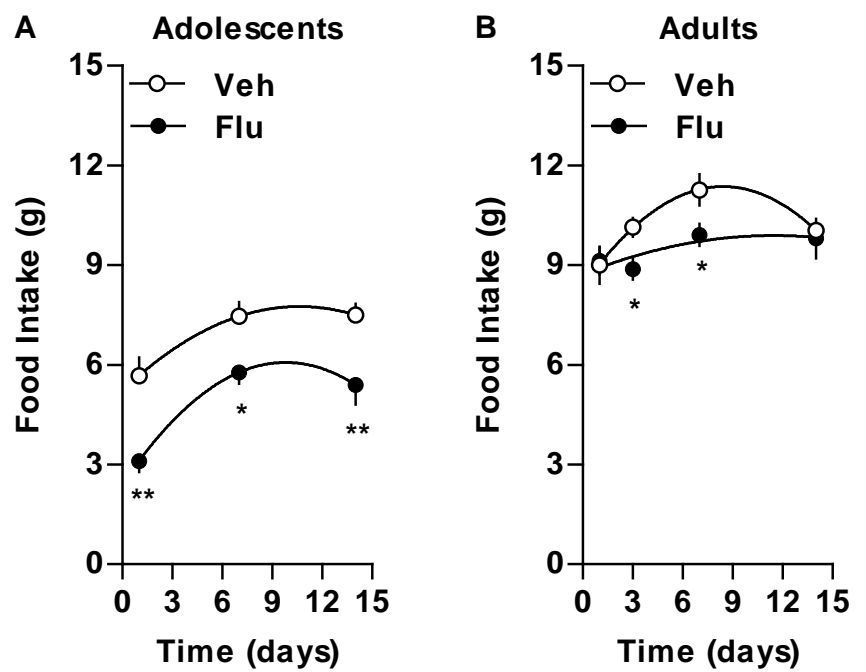
Fig. 4
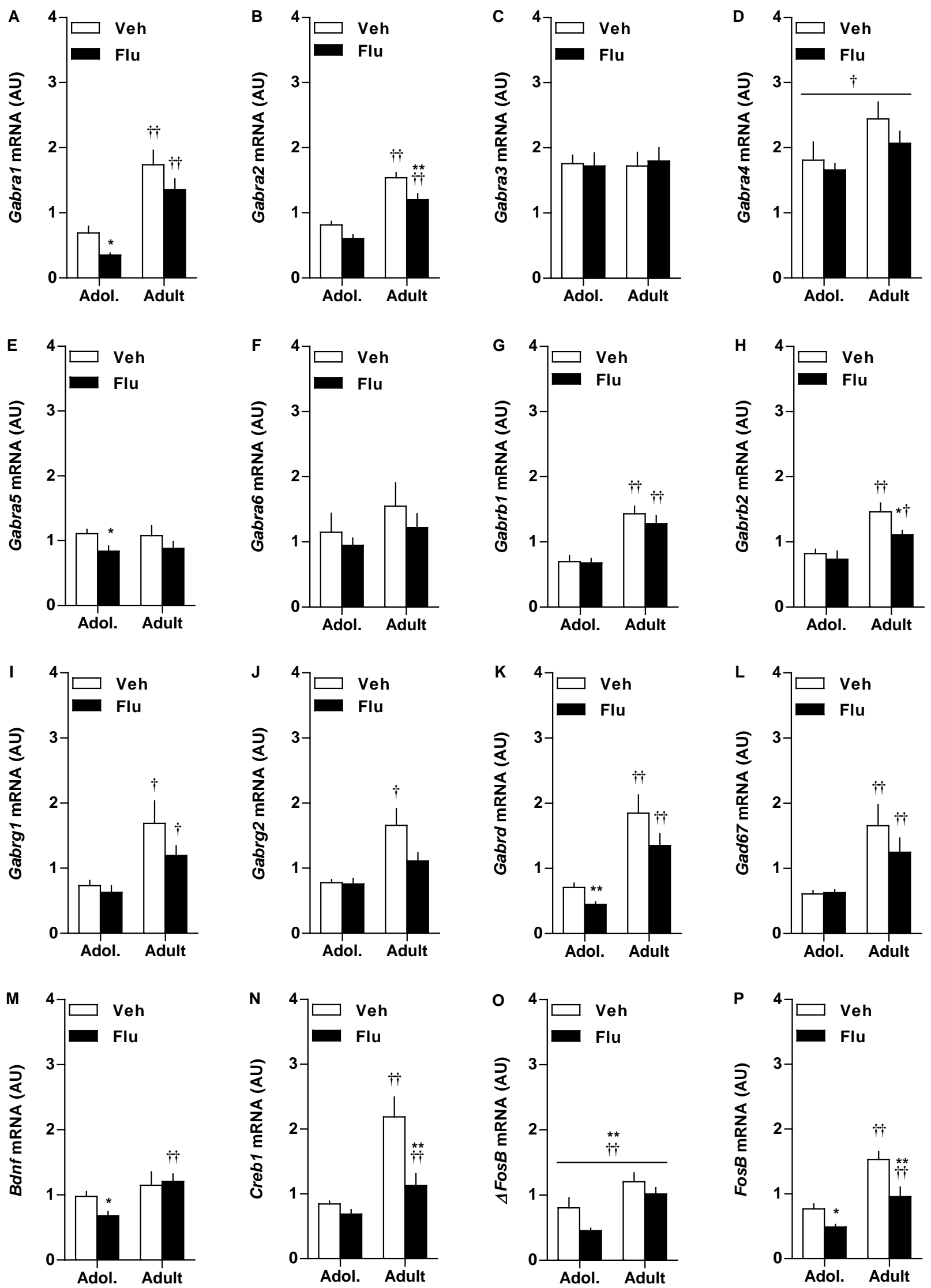
Fig. 5

A

Adult Fluoxetine In Vitro

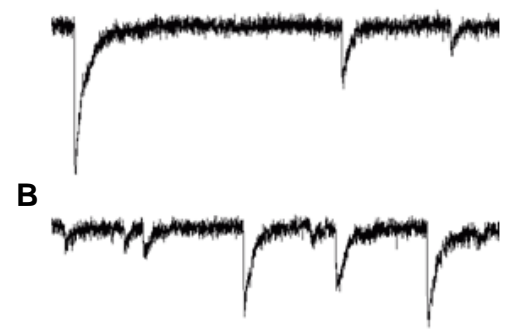

C

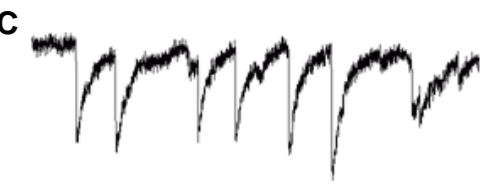

30 pA

$130 \mathrm{~ms}$
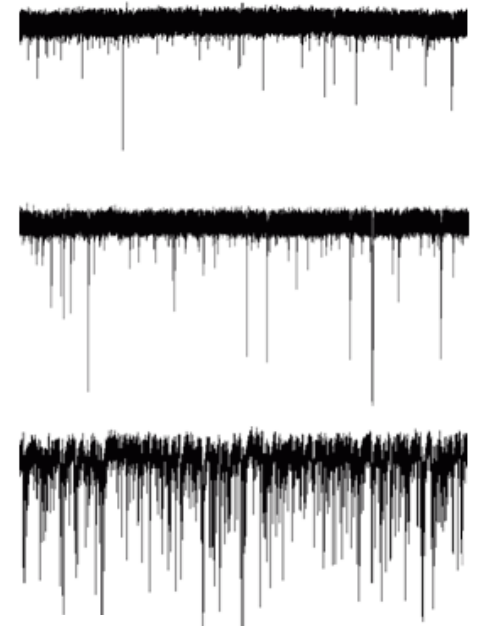

$30 \mathrm{pA} L$

$6500 \mathrm{~ms}$
Ensemble Average
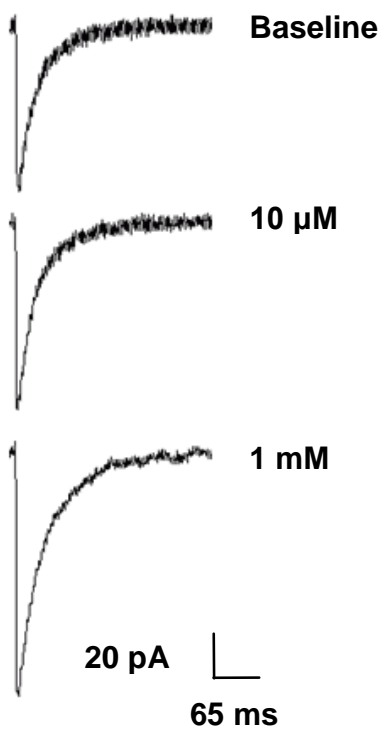

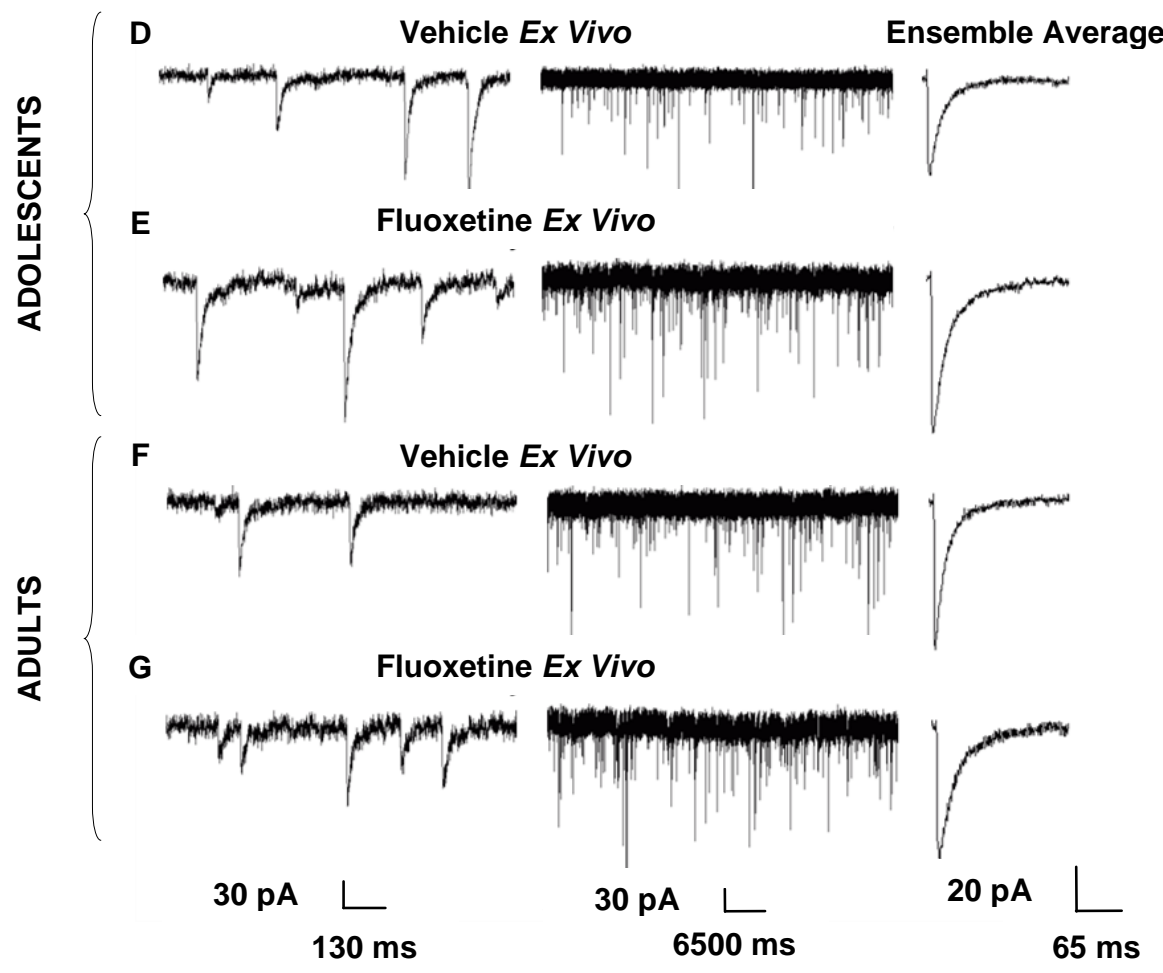


Fig. 6
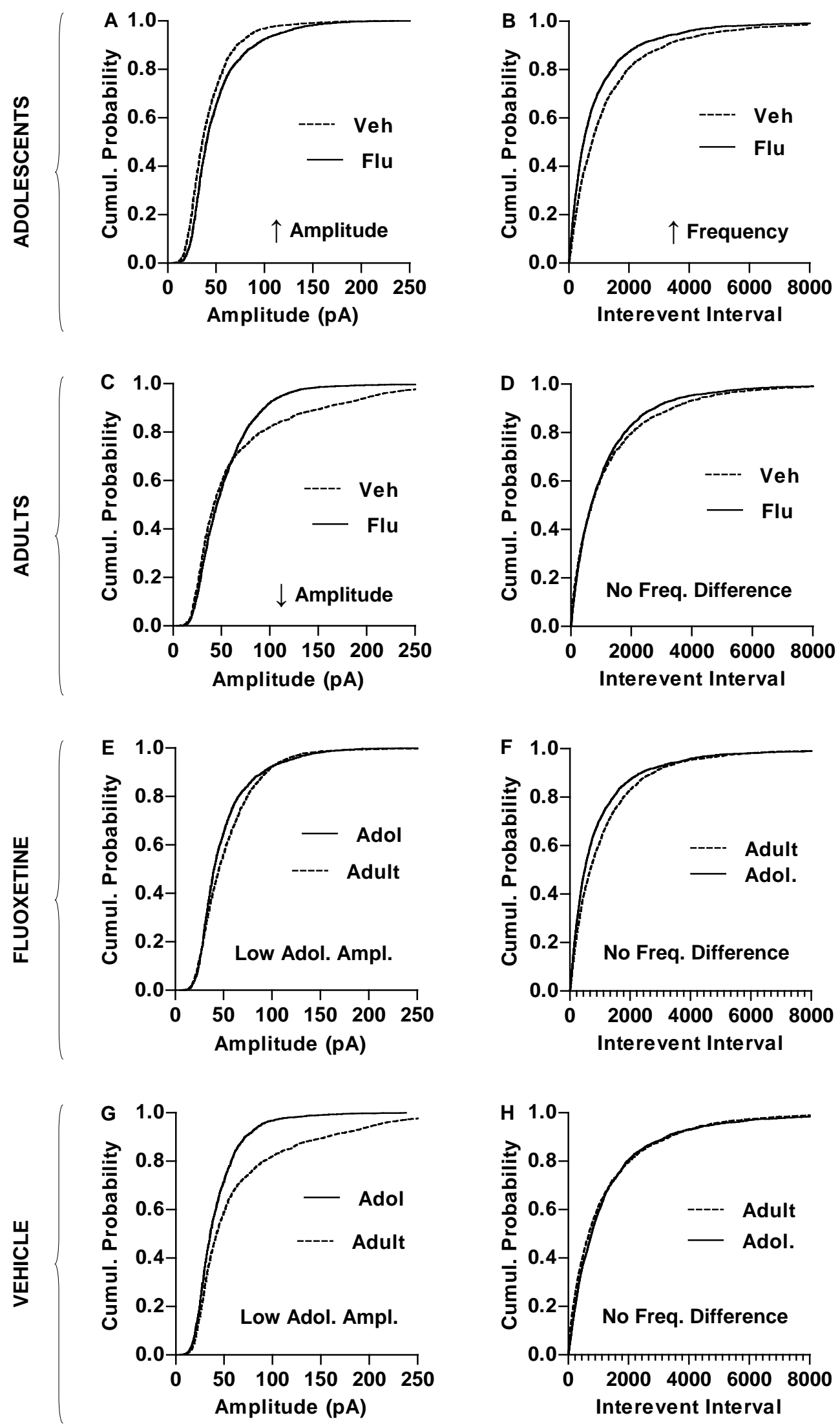